\title{
Pretty Face Matters: Relative Importance of the Face and Body Attractiveness in China
}

\author{
Pei-Luen Patrick Rau, Yun Gong, Chunping Zhuang \\ Department of Industrial Engineering, Tsinghua University, Beijing, China \\ Email: rpl@tsinghua.edu.cn
}

Received 5 January 2016; accepted 4 July 2016; published 7 July 2016

Copyright $\odot 2016$ by authors and Scientific Research Publishing Inc.

This work is licensed under the Creative Commons Attribution International License (CC BY). http://creativecommons.org/licenses/by/4.0/

\section{(c) (i) Open Access}

\begin{abstract}
This study gauges the relative importance of face and body attractiveness in terms of physical attractiveness in China. In the study of attitude, 653 participants were asked to prioritize face and body attractiveness in two mating contexts (short-term vs. long-term) via a survey. In the study of behavior, 232 participants were initially asked to remove either "face box" or "body box", and were afterwards shown images of 10 individuals of opposite sex and rated face, body and combined attractiveness of each individual. The results indicate that Chinese, independent of gender, assign a higher priority to face attractiveness than to body attractiveness. Body attractiveness is of greater importance to females for rating male attractiveness than to males for rating female attractiveness. Mating context does not imply a significant effect on face-body priority. Chinese conservative attitudes towards sexual cues in body images and short-term relationship are discussed to explain the findings.
\end{abstract}

\section{Keywords}

Face Attractiveness, Body Attractiveness, Face-Body Priority, Mating Context, Chinese Culture

\section{Introduction}

Physical attractiveness influences many aspects of human social interaction. One can refer to "attractiveness halo effect" or "beauty is good stereotype" to see that people are actually in a preferential manner to mate with, date, associate with, employ, and even vote for physically attractive individuals. People tend to ascribe positive personality characteristics to physically attractive individuals (Dion et al., 1972; Udry \& Eckland, 1984; Kalick et al., 1998).

Both men and women rate physical attractiveness among the top criteria they desire in a potential partner (Geher \& Kaufman, 2013). As evolutionary theories imply that physical traits are honest signals for good gene, 
age, fertility, and fecundity (Johnstone, 1997; Zahavi \& Zahavi, 1997), mass number of researches investigated how single physical trait, such as Body Mass Index (Tovée et al., 1999), Waist-hip ratio (Singh, 1993), face symmetry (Perrett et al., 1999), influence people's decision in overall attractiveness. Alternatively, other researches (Alicke et al., 1986; Thornhill \& Grammer, 1999; Peters, Rhodes, \& Simmoms, 2007; Currie \& Little, 2009; Confer et al., 2010) treated face and body as whole units, and studied the relative importance of face and body to overall attractiveness. Thornhill and Grammer suggested that women's face and body are considered to be a singal "ornament" that signal mate value, whereas Peters, Rhodes \& Simmoms (2007) found that face attractiveness and body attractiveness have independent contribution when judging overall attractiveness. Face and body attractiveness did not interact when an overall attractiveness judgment is made and face can better predict overall attractiveness than body. Their results validated the assumption that face and body attractiveness can be studied separately in a mating context. Currie \& Little (2009) and Confer et al. (2010) expanded the research in the relative importance of face and body attractiveness when choosing partner and pointed out that men prioritize facial cues over bodily cue in long-term relationship and inversely in short-term relationship. In contrast, women's relative preferences were unaffected by mating context, suggesting that women consistently prioritize facial cues over bodily cues.

The concept of the ideal body, however, is a cultural construct that has been influenced and continues to be influenced by culture and media. (Cunningham et al., 1995) studied the consistency of the perception of female physical attractiveness across culture groups and found that the ratings given by Asians (also confirmed by the second study with Taiwanese) were less influenced by model's sexual maturity and expressive features. (Swami et al., 2006) studied the relative contribution of Body Mass Index (BMI) and Waist-hip ratio (WHR) to female's physical attractiveness among both British and Japanese males and indicated that Japanese participants had significantly higher preference in women with lower WHR and more reliant on body shape than British.

This study aimed to investigate the relative importance of face and body attractiveness among Chinese participants, considering the particularities of Chinese culture compared to western culture. In historical China, Confucian ideals of patriarchal dominance have perpetuated a sexually conservative behavior for women and a permissive behavior for men (Lau, 1995). While in the Maoist period, individual desires, including sex are repressed by the government (Wehrfritz, 1996). Most Chinese people at that age wore similar, colorless clothes. People had prejudice to women who used cosmetics or permed their hair, and also to men who wear sunglasses or peaked cap. It was until Deng Xiaoping's Open-door Policy that sexual revolution has begun with the increasing globalization and modernization (Jeffreys, 2006). China is undergoing rapid changes in sexual mores, but there are still people who will be offended by sexually suggestive behavior. The Empress of China, the wildly popular historical TV series in 2014, was officially banned in China for sexy dressing. It returned on TV with all the scenes that would shown cleavage cut into close-up headshots. Under such a culture background, we are interested to know how Chinese differ from westerners in judging physical attractiveness and how mating context affect such judgment.

Two separate studies were carried out. In the study of attitude, we conducted a survey for self-report attitude on the priority of face or body under different contexts (short-term relationship vs. long-term relationship). To avoid the bias of self-report results, the second study with actual pictures shown to the participants was conducted. Participants were firstly shown to a picture of a model whose face and body were occluded. He/she had to make a box-removing decision between "face box" and "body box". And for the second task, they were shown images of 10 individuals of the opposite sex and rated independently the face, body and the combined attractiveness of each person. Results showed that Chinese participants, independent from gender, tend to assign a higher priority to face attractiveness than to body attractiveness. Body attractiveness is more important for females to judge overall attractiveness in comparison to males in China. Mating context does not imply a significant effect on the relative importance of face and body. The main contribution of this study is to extend previous study in eastern culture and providing cultural explanations to the inconsistent results.

\section{Study 1-The Study of Attitude}

\subsection{Method}

A questionnaire was posted on several Bulletin Board Systems in China for heterosexual participants to rate the relative importance of face attractiveness and body attractiveness in both short-term relationship and long-term relationship on a five-point Likert scale ( 1 -face most important, 5 -body most important). There were two 
main questions (originally in Chinese). The first question was asked under short-term relationship: "When you made your decision about whether you are going to date with someone for short-term relationship, i.e., one night stand, how did you prioritize information gathered from the face versus the body?" And the second was asked under long-term relationship: "When you made your decision about whether you are going to date with someone for long-term relationship, i.e., a committed relationship partner, how did you prioritize information gathered from the face versus the body?” Participants’ gender, age and relationship status were also collected.

\subsection{Participants}

A total of 653 responses (including 342 males) were collected. All of the participants are Chinese citizens with an average age of 25.86 years old ( $\mathrm{SD}=4.08) .44 \%$ are single, 33\% are in a relationship, 22\% are married and $1 \%$ is divorced. More than $90 \%$ are the Han people - the national majority.

\subsection{Results}

Mean ratings of the relative importance of face and body attractiveness in both mating contexts were listed in Table 1. Results showed that males assigned a higher priority to face attractiveness in both mating contexts. For female participants, they also prioritize face over body in short-term relationship, but in long-term relationship, female tend to pay more attention to body attractiveness.

T-test was conducted in each gender to test the influence of mating context. The results indicated a significant difference ( $p=0.000$, cohen's $\mathrm{d}=0.323$ — small effect size) in female participants and a non-significant difference ( $p=0.160)$ in males. In the study of attitude, Chinese females, but not Chinese males, showed a slight condition-dependent attractiveness judgment mechanism to prioritize body cues over face in long-term relationship and shift to face cues in short-term relationship. This is a reverse result to previous studies where condition-dependent attractiveness judgment was significantly found in males, but not females (Currie \& Little, 2009; Confer et al., 2010).

\section{Study 2: The Study of Behavior}

As the ratings in study 1 relied on participants’ personal imagination and experience, we conducted study 2 to avoid self-report bias by providing real model images. The study comprises 3 steps: obtaining images, standardizing images, and rating the images.

\subsection{Method}

\section{Obtaining Images}

To enrich the diversity of attractiveness, images were taken from 20 models (10 males and 10 females) that were recruited from 3 sources: advertising on the campus bulletin board; recruiting from film company and personal relationship. 75\% of them were university students (mainly from Beijing and Taiwan), and the rest were figurants from a film company.

Participants were informed about the purpose of the study and the way in which the images would be used. After informed consent, participants were required to put on standard clothes (black swim trunks and black vest), take off watches, and other decorators. Females were asked to tie their hair back with no fringe left (Currie and Little (2009) suggested that models should wear tight-fitting lined undergarment so that their body shapes can be shown closer to their true situation). One close-up shot of the participants' faces (with a neutral expression) and two full-length shots of their heads and bodies (neutral standing gesture with hands on the side of the body; one front shot, and one side shot) were taken using a Sony N5 digital camera from a height of $110 \mathrm{~cm}$ and a distance of $270 \mathrm{~cm}$. Photos were taken under symmetric lighting conditions.

Table 1. Ratings of the relative importance of face attractiveness and body attractiveness in both mating context (1-face most important, 5-body most important).

\begin{tabular}{ccccc} 
& Male $\mathrm{LT}^{*}$ & Male ST & Female LT & Female ST \\
\hline Mean (SD) & $2.80(0.903)$ & $2.70(0.946)$ & $3.16(0.886)$ & $2.87(0.885)$ \\
\hline
\end{tabular}

*ST—short-term relationship, LT—long-term relationship. 


\section{Standardizing images}

The images were standardized to face images and body images. Face images were presented at 133 pixels in height and 150 pixels in width so that most of the hair was covered. Front body images were presented at 150 pixels in width and side body images were presented at 137 pixels in width for male and 131 pixels in width for female. The height of body images varied according to the height of the model. All the images were scaling down by the same rate so that the relative scale of the body dimension was unchanged. All the other potential confounding information from the participants, such as hairstyle, tan line and scars were removed from the images.

\section{Material and procedure}

The ratings of the images were done anonymously via a specially designed website. After a brief introduction to the purpose of the experiment and demographic information (age, marriage, and gender) collection, the participants were randomly assigned to one of the mating contexts, either long-term or short-term. A picture of an opposite-gender model with one box covering his/her head and the other covering his/her body was presented to the participants. The participants could only choose to remove one of them and obtained the information that could help them choose partner. Then, 10 sets of body images and 10 face images of opposite-gender models were presented sequentially in a randomized order. The participants were asked to rate the attractiveness of each image on a 7-point likert scale ( 1 for very unattractive and 7 for very attractive). A measurement tape was placed beside each body image so that the participants would have a correct sense of height. After this, they were also asked to rate the whole-body images - each page with one face image on the top and two body images on the bottom. The pages were also shown in a randomized order. We adopted the top-bottom kind of combination (See Figure 1) instead of presenting the model in the natural way (face connected to the body) because 1) the face presented in the natural way will be smaller than the face images presented independently which will potentially affect the ratings. 2) factors such as hairstyle will be hard to control in a natural way. Ratings for acquaintance will be eliminated from the final ratings.

The participants were recruited by posting links on the SNS platforms and by sending emails to potential participants who were known to the author. We also encouraged the participants to forward the link to other people they knew.

\subsection{Participants}

A total of 131 males aged $18-30($ mean $=21.83 \mathrm{SD}=1.89)$ and 101 females aged $18-29($ mean $=21.5 \mathrm{SD}=$ 1.88) participated in rating the images. All the participants were reported to be heterosexual. 8 of them reported to be married.

\subsection{Results}

\section{Which part to see? Face or body?}

The results of box choice (see Table 2) indicated a general trend of choosing to remove face box rather than removing body box in both male raters (long-term: $81 \%$ vs $19 \%$, short-term: $73 \%$ vs $27 \%$ ) and female raters (long-term: $71 \%$ vs $29 \%$, short-term: $61 \%$ vs $39 \%$ ) in both mating contexts. In spite of this, Female raters assigned more priority to body compared to males, which is also consistent with the result of the study of attitude.

To evaluate the effect of mating context, cross-tabulation chi-square test was employed which revealed no significant difference between two mating context in either male participants $(p=0.259)$ or in female participants $(p=0.291)$. It indicates that the face-body choices to box removal task is not significantly influenced by mating context for both genders. This result is partially consistent with that of study 1 . It repeats the contextindependent behavior in attractiveness judgment for male raters, but the slight context-dependent behavior we observed with females in study 1 is not repeated. We believe the disparity between the two results is acceptable as the effect size of mating context on face-body priority in study 1 is small. It sheds lights on the possiblity that females, though, think they prioritize body over face in a long-term relationship, they actually still stick to face cues in reality. And in this study we adopted the result from the study of behavior that mating context does not imply a significant effect on the relative importance of face and body.

\section{How face and body cues contribute to overall attractiveness?}

Mean ratings and standard deviations given to each model's face, body and overall attractiveness are given in Table 3. Desciptive analysis showed that the combined ratings for most models lied between their face ratings 


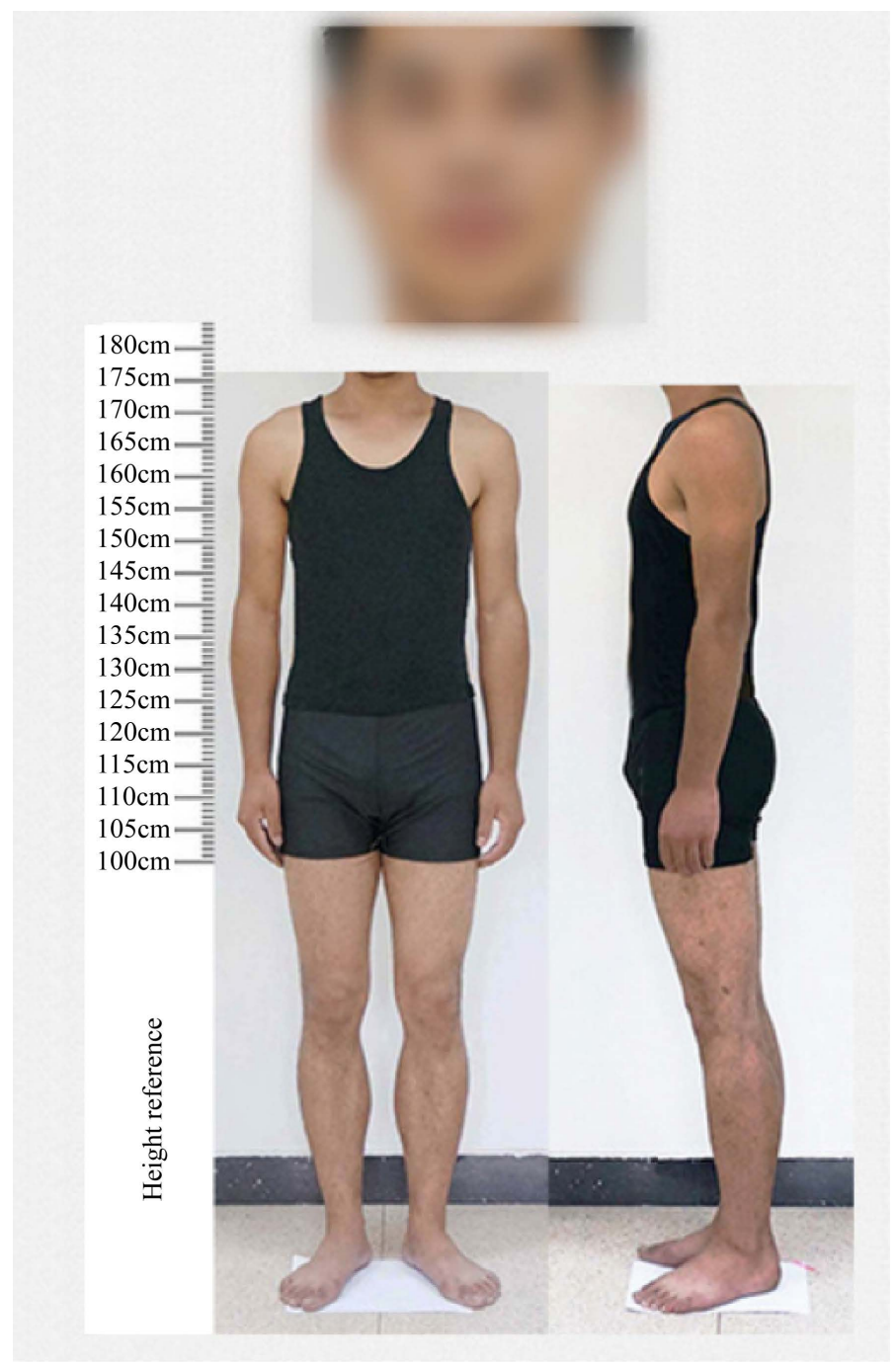

Figure 1. The top-bottom combination of face image and body image. The face image is intentionally blurred for publication purpose.

Table 2. Frequency and percentage of box choice (remove face box or body box) under long-term and short-term condition.

\begin{tabular}{ccccc} 
& \multicolumn{2}{c}{ Long-term } & \multicolumn{2}{c}{ Short-term } \\
\cline { 2 - 5 } & Body & Face & Body & Face \\
\hline Male rater & $11(19 \%)$ & $47(81 \%)$ & $20(27 \%)$ & $53(73 \%)$ \\
Female rater & $15(29 \%)$ & $37(71 \%)$ & $19(39 \%)$ & $30(61 \%)$ \\
\hline
\end{tabular}

and body ratings, and were closer to the face ratings than to the body ratings.

But there are exceptions, such as Female 4 and Male 7, whose combined ratings are even lower than rated separately. One possible reason for this is that both the body ratings and face ratings for Female 4 and Male 7 are low. And the reason for other exceptions, such as Female 5, whose combined rating is higher than both of the separate ratings, and Male 4 whose combined ratings is closer to body rating than to face rating can be attributed to the high ratings for both face and body.

Calculating the standardized correlation of face rating, body rating, and combined rating (See Table 4) given by male and female raters, we found a strong linear relationship (cov $=0.991,0.889,0.881,0.825)$ between face attractiveness and overall attractiveness. This was in accordance with the results of box-removal experiment. 
Table 3. Frequency and percentage of box choice (remove face box or body box) under long-term and short-term condition.

\begin{tabular}{|c|c|c|c|c|c|c|c|c|c|c|c|}
\hline Male raters & & Female 1 & Female 2 & Female 3 & Female 4 & Female 5 & Female 6 & Female 7 & Female 8 & Female 9 & Female 10 \\
\hline \multirow[t]{2}{*}{ Body } & Mean & 3.38 & 3.45 & 2.48 & 2.35 & 3.16 & 3.25 & 4.13 & 3.22 & 2.97 & 3.44 \\
\hline & SD & 1.24 & 1.28 & 1.13 & 1.29 & 1.30 & 1.40 & 1.39 & 1.32 & 1.15 & 1.29 \\
\hline \multirow[t]{2}{*}{ Face } & Mean & 2.29 & 1.85 & 3.09 & 2.12 & 3.15 & 1.59 & 3.53 & 1.62 & 3.77 & 1.98 \\
\hline & SD & 1.10 & 0.99 & 1.43 & 1.10 & 1.24 & 0.79 & 1.32 & 0.87 & 1.26 & 1.03 \\
\hline \multirow[t]{2}{*}{ Combined } & Mean & 2.62 & 2.06 & 2.88 & 1.87 & 3.27 & 1.76 & 4.02 & 1.85 & 3.64 & 2.26 \\
\hline & SD & 1.33 & 1.15 & 1.48 & 1.04 & 1.45 & 1.07 & 1.59 & 1.04 & 1.43 & 1.30 \\
\hline Female raters & & Male 1 & Male 2 & Male 3 & Male 4 & Male 5 & Male 6 & Male 7 & Male 8 & Male 9 & Male 10 \\
\hline \multirow[t]{2}{*}{ Body } & Mean & 3.69 & 3.98 & 3.35 & 3.76 & 3.29 & 3.10 & 2.21 & 4.06 & 4.03 & 3.98 \\
\hline & SD & 1.47 & 1.36 & 1.28 & 1.52 & 1.34 & 1.49 & 1.13 & 1.36 & 1.42 & 1.57 \\
\hline \multirow[t]{2}{*}{ Face } & Mean & 2.64 & 2.71 & 2.04 & 3.20 & 3.37 & 1.75 & 1.84 & 2.03 & 1.84 & 2.94 \\
\hline & SD & 1.26 & 1.22 & 0.95 & 1.43 & 1.36 & 1.06 & 1.00 & 1.05 & 1.07 & 1.48 \\
\hline \multirow[t]{2}{*}{ Combined } & Mean & 2.98 & 3.27 & 2.28 & 3.51 & 3.34 & 1.98 & 1.76 & 2.56 & 2.55 & 3.50 \\
\hline & SD & 1.42 & 1.36 & 1.14 & 1.64 & 1.45 & 1.26 & 1.06 & 1.33 & 1.36 & 1.61 \\
\hline
\end{tabular}

Table 4. The standardized correlation of face rating, body rating and combined rating.

\begin{tabular}{ccccc}
\hline & \multicolumn{2}{c}{ Long-term } & \multicolumn{2}{c}{ Short-term } \\
\hline Correlation with combined image & Face & Body & Face & Body \\
\hline Male & 0.991 & 0.460 & 0.889 & 0.446 \\
Female & 0.881 & 0.473 & 0.825 & 0.532 \\
\hline
\end{tabular}

To further explore the relationship between combined attractiveness ratings and separate attractiveness ratings for face and body, respondents' ratings of attractiveness were analyzed using a univariate general linear model (GLM). The ratings given to the face and the body images separately were entered as covariates (predictors) of the dependent variable (rating given to the combined images). The model being viewed (1 - 10) was entered as a random factor, and the condition under which the images were being assessed (i.e., for a short-term relationship or a long-term relationship) was entered as a fixed factor. Since 1) fixed factor is categorical variable and covariates are interval variable. 2) The dependent variable is linear with respect to the covariates 3 ) the regression coefficient of the covariates remain the same under all categories. 4) the fixed variable and the covariates are orthogonal, the condition of applying GLM analysis is satisfied.

For male, the GLM explained $59.3 \%$ of the variance of ratings given to the combined image. Ratings of face $\left(\mathrm{F}_{1,1288}=676.695, p<0.001\right)$ and body images $\left(\mathrm{F}_{1,1288}=153.152, p<0.001\right)$ are both significant positive predictors of the ratings of combined images. Face image is the stronger predictor $\left(\beta=0.633, \eta_{p}^{2}=0.344\right)$ compared to body image $\left(\beta=0.267, \eta_{\mathrm{p}}^{2}=0.106\right)$. The model being viewed is also a significant factor of the total attractiveness. $\left(F_{1,9}=1.436, p=0.008\right)$. This result indicates that males will give more priority to face attractiveness while judging the overall attractiveness of females.

For females, the GLM explained 55\% of the variance of ratings given to the combined image. Ratings of face $\left(\mathrm{F}_{1,988}=551.561, p<0.001\right)$ and body images $\left(\mathrm{F}_{1,988}=109.099, p<0.001\right)$ are both significant positive predictors of the ratings of combined images. Face image is the stronger predictor $\left(\beta=0.652, \eta_{p}^{2}=0.358\right)$ compared to body image $\left(\beta=0.248, \eta_{p}^{2}=0.099\right)$. The model being viewed is also a significant factor of the total attractiveness. $\left(F_{1,9}=12.024, p<0.001\right)$. This result indicates that females will also give more priority to face attractiveness while judging the overall attractiveness of males. 


\section{Discussion}

\subsection{Face Attractiveness: Stronger Predictor to Overall Attractiveness than Body}

According to our results, face attractiveness is the major factor in judging overall attractiveness of opposite gender in China, for both genders and under both mating contexts (long-term and short-term). This dominance of face attractiveness in physical attractiveness judgment is consistent with most western researches (Confer et al., 2010; Currie \& Little, 2009) and is even more significant with Chinese participants than with western participants.

\subsection{Body Attractiveness: Generally Less Important than Face, But Means More to Females than to Males}

The reason why body attractiveness is of less importance than face in China is rooted in Chinese culture. As Chinese saying goes: sturdily built, but simple-minded. Ancient Chinese have realized that physical strength and athleticism is no longer an absolute indicator of a man's ability to acquire resources in the society. Instead, men with broad mind, wisdom or literary talents are more likely to acquire power and wealth under the Imperial Examination System. The expectation for females in the modern society is changed as well. Information about sexual maturity, the ability to produce children, and current pregnancy status, such traditional information that men could concern to judge the current fertility and reproductive value of a female is less important than the personality, ability nowadays.

Our result regarding mating context is, however, inconsistent with previous western studies where males are found to pay more attention to body attractiveness than females do, especially in short-term relationship. Both of the studies we conducted revealed a higher priority of body attractiveness for Chinese females to choose mates than for Chinese males. We didn't include a post-interview after the ratings which is a limitation of this study, but there is a possible reason that social pressure in China prevents men to freely express their preference in women's body. A man who showed his interest in women's body would somehow be offensive, while in contrast, a woman wouldn't be judged in the same way around.

\subsection{Mating Context: Does Not Largely Affect Relative Importance of Face and Body}

Another result from our study, which is inconsistent with western studies, is that mating context does not largely affect relative importance of face and body. Unlike the previous results (Currie \& Little, 2009; Confer et al., 2010), which pointed out that men significantly prioritize facial cues over bodily cues in long-term relationship and inversely in short-term relationship, no significant differences were found between mating contexts when Chinese males judge the relative importance of face and body.

Feedbacks from the participants may help explain this result. Some participants complained the experiment being too sexual liberated (having scenarios such as one-night stand). Some male participants who still adhered to traditional sexual mores reported that they might give the same ratings under different conditions because they didn't have an experience of having a short-term relationship. Conservative attitudes towards sexual cues and the social repression in short-term relationship may explain why the context-dependent behavior in judging attractiveness was not found in this study.

Though China is undergoing a rapid change in sexual mores, these feedbacks still indicated a relatively conservative attitude toward sexual cues. Pan (2006) proposed that sex in China should be understood in its relationship with marriage. This is consistent with our participants' replies in that some Chinese people still cannot properly accept short-term relationship. This may explain why we didn’t observe a different rating pattern between two mating contexts.

The limitations of this research mainly lie in the following aspects. First, most of the ratings for the models are lower than 4 in a 7-point Likert Scale. It is possible that the models being not so attractive would have an impact on the results. Second, there are no enough post experiment interviews to help us explain the participants' choices and their current emotional states. In further studies, we would focus more on people's choice context and their explanations to their choices.

As the first study concerning the relative importance of face and body in judgment of the physical attractiveness of opposite sex based on a Chinese sample, this study documents both similarity and differences between Chinese and westerners in judging what is beauty. Face attractiveness better predicts overall attractiveness than 
body in both western culture and eastern culture. But the context-dependent behavior for male to judge physical attractiveness is not observed with Chinese male participants. Body attractiveness is more important for male in China. It provides evidence of the significant effect of culture on judgment of the physical attractiveness. Such study may help people understand the culture-dependent behavior and act appropriately on cross-cultural events.

Attractive faces can attract more attention of people, so in the communication industries, like digital advertisements, video industry, and even resume, it is better to show attractive faces. One can refer to the widely spread picture in China comparing the difference in body shape between the Chinese star Li Bingbing and Western star Katy Perry to see the importance of face attractiveness in China. As for the implication, with the development of Internet, advertisement industry, video industry, and also cosmetics industry are having more and more impacts on people's daily lives. For providing attractive advertisements, videos, and making people more and more attractive, more and more confident about themselves, such research findings, as ours, can be beneficial.

\section{References}

Alicke, M. D., Smith, R. H., \& Klotz, M. L. (1986). Judgments of Physical Attractiveness: The Role of Faces and Bodies. Personality and Social Psychology Bulletin, 12, 381-389. http://dx.doi.org/10.1177/0146167286124001

Confer, J. C., Perilloux, C., \& Buss, D. M. (2010). More than Just a Pretty Face: Men’s Priority Shifts toward Bodily Attractiveness in Short-Term versus Long-Term Mating Contexts. Evolution and Human Behavior, 31, 348-353. http://dx.doi.org/10.1016/j.evolhumbehav.2010.04.002

Cunningham, M. R., Roberts, A. R., Barbee, A. P., Druen, P. B., \& Wu, C. H. (1995). "Their Ideas of Beauty Are, on the Whole, the Same as Ours”: Consistency and Variability in the Cross-Cultural Perception of Female Physical Attractiveness. Journal of Personality and Social Psychology, 68, 261. http://dx.doi.org/10.1037/0022-3514.68.2.261

Currie, T. E., \& Little, A. C. (2009). The Relative Importance of the Face and Body in Judgments of Human Physical Attractiveness. Evolution and Human Behavior, 30, 409-416. http://dx.doi.org/10.1016/j.evolhumbehav.2009.06.005

Dion, K., Berscheid, E., \& Walster, E. (1972). What Is Beautiful Is Good. Journal of Personality and Social Psychology, 24, 285. http://dx.doi.org/10.1037/h0033731

Geher, G., \& Kaufman, S. B. (2013). Mating Intelligence Unleashed: The Role of the Mind in Sex, Dating, and Love. Oxford: Oxford University Press.

Jeffreys, E., Ed. (2006). Sex and Sexuality in China. London: Routledge.

Johnstone, R. A. (1997). The Evolution of Animal Signals. Behavioural Ecology: An Evolutionary Approach, 4, $155-178$.

Kalick, S. M., Zebrowitz, L. A., Langlois, J. H., \& Johnson, R. M. (1998). Does Human Facial Attractiveness Honestly Advertise Health? Longitudinal Data on an Evolutionary Question. Psychological Science, 9, 8-13. http://dx.doi.org/10.1111/1467-9280.00002

Lau, M. P. (1995). Sex and Civilization in Modern China. Transcultural Psychiatric Research Review, 32, 137-156. http://dx.doi.org/10.1177/136346159503200202

Pan, S. M. (2006). Transformation in the Primary Life Cycle: The Origins and Nature of China’s Sexual Revolution. In E. Jeffreys (Ed.), Sex and Sexuality in China (pp. 21-42). Abingdon-on-Thames: Routledge.

Perrett, D. I., Burt, D. M., Penton-Voak, I. S., Lee, K. J., Rowland, D. A., \& Edwards, R. (1999). Symmetry and Human Facial Attractiveness. Evolution and Human Behavior, 20, 295-307. http://dx.doi.org/10.1016/S1090-5138(99)00014-8

Peters, M., Rhodes, G., \& Simmons, L. W. (2007). Contributions of the Face and Body to Overall Attractiveness. Animal Behaviour, 73, 937-942. http://dx.doi.org/10.1016/j.anbehav.2006.07.012

Singh, D. (1993). Body Shape and Women’s Attractiveness. Human Nature, 4, 297-321. http://dx.doi.org/10.1007/BF02692203

Swami, V., Caprario, C., Tovée, M. J., \& Furnham, A. (2006). Female Physical Attractiveness in Britain and Japan: A Cross-Cultural Study. European Journal of Personality, 20, 69-81. http://dx.doi.org/10.1002/per.568

Thornhill, R., \& Grammer, K. (1999). The Body and Face of Woman: One Ornament That Signals Quality? Evolution and Human Behavior, 20, 105-120. http://dx.doi.org/10.1016/S1090-5138(98)00044-0

Tovée, M. J., Maisey, D. S., Emery, J. L., \& Cornelissen, P. L. (1999). Visual Cues to Female Physical Attractiveness. Proceedings of the Royal Society of London B: Biological Sciences, 266, 211-218. http://dx.doi.org/10.1098/rspb.1999.0624

Udry, J. R., \& Eckland, B. K. (1984). Benefits of Being Attractive: Differential Payoffs for Men and Women. Psychological Reports, 54, 47-56. http://dx.doi.org/10.2466/pr0.1984.54.1.47 
Wehrfritz, G. (1996). Unbuttoning a Nation. International Newsweek, 127, 38-40.

Xiao, Z., Mehrotra, P., \& Zimmerman, R. (2011). Sexual Revolution in China: Implications for Chinese Women and Society. AIDS Care: Psychological and Socio-medical Aspects of AIDS/HIV, 23, 105-112. http://dx.doi.org/10.1080/09540121.2010.532537

Zahavi, A., \& Zahavi, A. (1997). The Handicap Principle: A Missing Piece of Darwin’s Puzzle. Oxford: Oxford University Press.

Submit or recommend next manuscript to SCIRP and we will provide best service for you:

Accepting pre-submission inquiries through Email, Facebook, Linkedin, Twitter, etc A wide selection of journals (inclusive of 9 subjects, more than 200 journals)

Providing a 24-hour high-quality service

User-friendly online submission system

Fair and swift peer-review system

Efficient typesetting and proofreading procedure

Display of the result of downloads and visits, as well as the number of cited articles

Maximum dissemination of your research work

Submit your manuscript at: http://papersubmission.scirp.org/ 